\title{
MODIFIED LENDRUM'S TECHNIQUE TO DEMONSTRATE METACHROMASIA OF BRAIN SAND IN PINEAL GLAND
}

\author{
Vasudha Kulkarni *1, Ramesh BR ${ }^{2}$.
}

*1 Associate Professor, Department of Anatomy, Dr.B.R. Ambedkar M edical College, Bangalore, Karnataka, India.

2 Professor and Head, Department of Anatomy, Dr.B.R. Ambedkar M edical College, Bangalore, Karnataka, India.

\section{ABSTRACT}

Background: Tissue components such as amyloid, mast cell granules and sulfated compounds stain differently from original dye. This is known as metachromasia. Calcium aggregations are known to exhibit metachromasia in certain situations. Local factor which could cause metachromasia is high levels of chondroitin sulfate in tissues undergoing calcification. Pineal gland is one such tissue with calcific concretions in its parenchyma known as Corpora arynecea/ Brain sand.

Objective: The objective of the present study was to demonstrate metachromasia of these calcific concretions using modified Lendrum's technique.

Methodology and Results: By using modified Lendrum's technique, metachromasia was demonstrated by corpora arenecea of pineal gland for aqueous methylene blue.

Conclusion: This technique is of importance in histopathology as pineal gland has clinical relevance. The hormone melatonin secreted in excess by pineal gland is associated with depression, peptic ulcers and sexual dysfunction. Melatonin deficiency results in insomnia.

KEY WORDS: Pineal gland, Corpora arynecea, Metachromasia, Brain sand.

Address for Correspondence: Dr. Vasudha Kulkarni, Associate Professor, Department of Anatomy, Dr.B.R. Ambedkar M edical College, Bangalore, Karnataka, India. E-Mail: vasu_anil77@ rediffmail.com

\section{Access this Article online}

\section{Quick Response code}

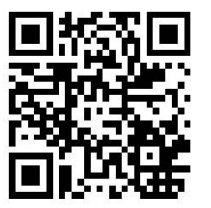

DOI: $10.16965 /$ ijar.2016.492

Web site: International Journal of Anatomy and Research

ISSN 2321-4287

www.ijmhr.org/ijar.htm

Received: 29 Nov 2016

Peer Review: 29 Nov 2016

Revised: None
Accepted: 04 Jan 2017

Published (0): 31 Jan 2017

Published (P): 31 Jan 2017

\section{INTRODUCTION}

Metachromasia is a phenomenon that will differentiate particular tissue components by giving them a different colour to that of original dye [1]. Tissue components often demonstrated by metachromatic stains are amyloid material, mucin, cartilage. Sulfated substances are highly metachromatic e.g. mast cell granules. M etachromatic stains are basic dyes belonging to aniline group. Some of the common metachromatic dyes are: M ethylene blue, M ethyl violent, Thionine, Crystal violet, Toluidine blue etc., [2].
Studies have shown that tissues which undergo calcification such as skeletal muscle can exhibit metachromasia with toluidine or methylene blue. Local factor which could cause such a change is high level of chondroitin sulphate [3]. Calcium deposits are a normal feature of pineal gland, commonly known as Corpora arynecea/ brain sand. The present study aims at demonstrating metachromasia of corpora arynecea or brain sand of pineal gland.

Pineal gland or Pineal body or Epiphysis cerebri is a pea sized endocrine gland. It is conical in 
shape. The gland weighs about 0.1gm. Melatonin was isolated from the Gland, Lerner, 1958 $[4,5]$. Melatonin plays an important role in maintenance of homeostasis involving gonads, hypophysis and melanin. This hormone modulates wake/sleep process in higher vertebrates [6]. There is evidence that melatonin secretion by the pineal gland is affected by exposure to electromagnetic fields [7]. The cells of retina, iris, skin and pineal gland have light sensing capabilities. Histopathological evaluation of pineal gland is important for understanding neoplastic and non-neoplastic lesions of some organs $[8,9]$.

Objectives: To exhibit metachromasia of corpora arynecea using modified Lendrum's technique, to compare microscopic structure of brain sand of pineal gland stained by hematoxylin and eosin stain with modified Lendrum's technique for efficacy, to identify type of intrapineal calcification

\section{MATERIALS AND METHODS}

Two pineal glands were dissected from cadaveric brain specimens, fixed in $10 \%$ formal saline, processed and embedded in paraffin blocks and $5 \mu$ thick 50 serial sections were taken. The sections were stained with:

\section{a. Hematoxylin and Eosin staining \\ b. Modified Lendrum's technique}

Staining with Hematoxylin and Eosin [10]: Sections were brought to water. The sections were stained with Harris hematoxylin for 5 minutes, rinsed in tap water, differentiated in 1\% acid alcohol for 5-30 seconds. Blueing was done under tap water. The slides were stained with Eosin for 2-5 minutes, dehydrated, cleared with xylene and mounted with DPX.

\section{Staining with Modified Lendrum's technique} [11]: Sections were brought to water via xylene and ethanol. They were placed in methylene blue solution for 3 minutes then differentiated in formalin until corpora arynecea is distemper green in colour and contrasts well with the pineal tissue. The sections were then placed in sodium chloride solution for 5 minutes, rinsed well with tap water. All the water was drained from the slide until just damp and mounted with DPX. This procedure can be considered modified because instead of methyl violet, methylene blue was used.
The pineal gland with Hematoxylin and Eosin staining under low power microscopy shows lobulation (Figure 1). Two types of cells are seen: Pinealocytes, the chief cells and astrocytes, the supporting cells. Pinealocytes are irregular in shape with elongated cytoplasmic processes which are arranged in radiating manner, connected to adjacent cells, also attaching to walls of blood vessels. The cells are arranged in cluster of 2-3. Nucleus of pinealocyte is oval in shape. Astrocytes are elongated cells interspersed between pinealocytes. These cells are darkly stained. Nucleus is ill defined in shape. Astrocytes arranged in chains of 2-3 cells. They are less numerous. The septa have numerous blood vessels and unmyelinated nerve fibres. The corpora arynecea (brain sand) are calcified masses in the parenchyma of varying sizes.

Modified Lendrum's technique demonstrates corpora arynecea as distemper green coloured masses in the pineal gland parenchyma (Figure 2 ). The background is bottle green in colour which can be attributed to melanin pigments present in human pinealocytes. They are more concentrated extra cellularly. The comparison of hematoxylin and eosin staining with modified Lendrum's technique showed brilliant staining of brain sand in latter technique.

Fig. 1: Pineal gland: Hematoxylin and eosin stain 10x10 magnification.

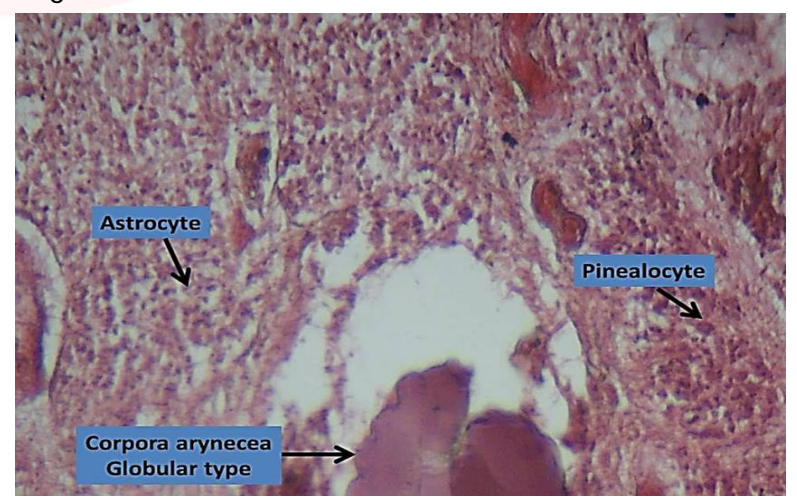

Fig. 2: Pineal gland: Modified Lendrum's technique (10x10 magnification).

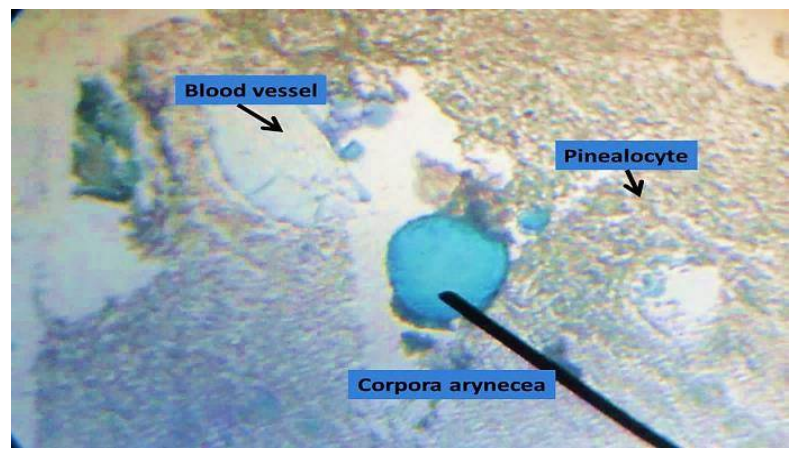


Fig. 3: Classification of Corpora arenecea.

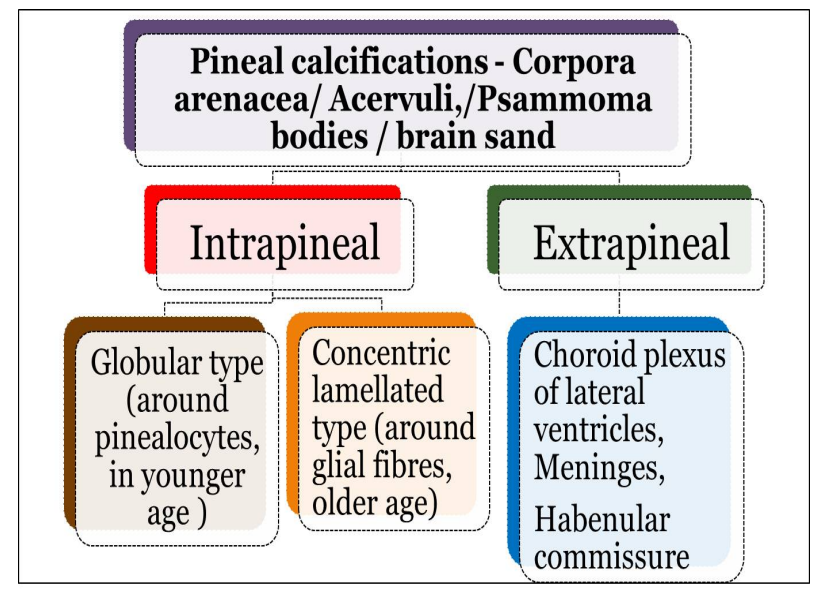

\section{DISCUSSION}

Corpora arynecea / Brain sand consists of calcium and magnesium salts, polypeptide hormones, produced by pineal neuroglia and neurons, combined with specific protein carriers. They are released by exocytosis. When released, the complex dissociates, hormones being exchanged for calcium ions. The calcium carrier complex so formed is deposited concentrically around exocytotic debris as corpora arynecea. The degree of calcification increases from younger to older age groups. Calcification occurs not only in the pineal gland but also in the capsule [12].

Corpora arynecea/ Brain sand of pineal gland can be broadly classified as given in figure 3 [8]. The presence of calcium alongside the cell membranes and that meningeal corpora arenacea are in the form of concentric lamellae $\&$ intrapineal as globular [12]. In the present sections of pineal glands, the corpora arynecea were globular in shape and around pinealocytes. This infers that the gland is younger in age (Fig 1\& 2).

Metachromasia is a unique staining phenomenon which demonstrates the ability of some tissue structures to aggregate dye particles, thus projecting a new colour. The most common group of dyes exhibiting this effect are members of the thiazine group (thionine, methylene blue, and toluidine blue). The tissues that can be stained metachromatically include mast cell granules, the matrix of cartilage, Wharton's jelly in umbilical cord, Nissl substance, some mucins, thyroid colloid, vitreous humor of eye, amyloid (with methyl violet dyes) etc., [13].
Principle of metachromasia is polymerization. Metachromasia takes place when certain negatively charged groups on the tissue react with cationic dyes. On polymerization, the original colour of the dye changes to another colour (eg. mast cell stain pink with toluidine blue) [14]. Factors which enhance metachromasia are increasing concentration of dye and decreasing temperature. This contributes to the efficiency of Van der Waal's forces by which the molecules are held together and intermolecular distances are reduced. $\mathrm{PH}$ and dye purity play a role in metachromatic staining. The aqueous environment also plays an important role in metachromatic staining; dehydration and clearing will usually destroy or diminish the staining [15].

Sources of affinity: The role of saturated salt solution in modified Lendrum's technique can be attributed to sodium chloride inhibiting leaching of the dye into the mountant. Its action is related to that of iodine in a Gram stain [16].

\section{Dye - tissue interactions in metachromasia:}

Normally, during Hematoxylin and Eosin staining, tissue components becoming preferentially stained by dyes with the opposite charges are not primarily driven by the electrical effects. The tissue components containing glycosaminoglycans (GAGs) can stain metachromatically with basic (cationic) dyes such as toluidine blue. Such processes are entropy driven with the electrical effects controlling selectivity. Strong electrical forces arising between ions are non-directed, longer-range attractions. These can contribute to affinity when dye and tissue component have charges of opposite sign [16]. M etachromasia was discovered in 1875 by Cornil, Jurgens, and Ranvier. Metachromasia is a phenomenon whereby a dye may absorb light at different wavelengths depending on its concentration and surroundings. It has the ability to change its colour without changing its chemical structure. The physical changes that bring about this colour change are a specialized, orderly form of dye aggregation. For metachromasia to occur there must be free electronegative groups on the surface of tissues. M etachromasia is caused by stacking of dye cations at the sites of high density of anionic groups in the tissue. Stacking shortens the wavelength of maximum absorption, a hypsochromic shift, so that the maximum 
wavelength in the spectrum of the transmitted light is longer making the observed colour red instead of blue. Substances that can be stained in this way are called chromotropes. The chromotropes carry acidic groups with a minimum density of not more than $0.5 \mathrm{~nm}$ between adjacent negatively charged groups. These alter the colour of metachromatic dyes. Principally, van der Waals forces hold the dye together to form dimers, trimers, or polymers. Other forms that play a lesser role are hydrogen and hydrophobic bonding. The dye exists in a normal monomeric (orthochromatic) form to a potential polymeric (metachromatic) form. The negative charges on the chromotropes attract the positively charged polar groups on the dye leading to dye-to-dye aggregation in a specialized orderly form forming a polymeric form. There are three forms of metachromasia alpha $(\alpha)$, beta $(\beta)$, and gamma $(\gamma)$ giving a range of colors [17].

Van der Waals attractions between metachromatic dye and polyanions contribute to affinity when binding to DNA and RNA, as does hydrophobic bonding. DNA, RNA and GAGs are then polyanionic, whilst most proteins are protonated and so polycationic. Thus basic dye cations exchange with mobile tissue cations associated with the various polyanions, a process termed "basic dyeing". This ion-exchange is entropy driven as it increases the randomness of the system. Since polycationic proteins are not associated with mobile cations, ion exchange cannot occur, minimising background staining. M etachromatic dyes do however distinguish GAGs from other polyanions [18].

In tissues with high concentration of anions for e.g. in sulphated mucopolysaccharides, the cationic dye molecules may be held in such close proximity to one another that van der Waal's forces can exert their influence and cause the dye to polymerize. Consequently,the colour changes. One important condition is the salt concentration. It was shown that in the absence of salt, sedimentation of the metachromatic compound does not occur in the presence of excess chondroitin sulfate. Salt is similarly required for adsorption of the metachromatic compound to the calcium salts [19]. In the present study, methylene blue was used instead of methyl violet for exhibiting metachromasia. This is because methylene blue at about 100,000 $x \mathrm{~g}$ consists of dye cations whereas chondroitin sulphate has polyanions in equal amounts. This finding suggests that a single compound of dye and chromotrope in solution is the cause of the metachromatic color. In pineal gland, the basis for metachromasia of corpora arnecea/ brain sand is selectivity for Chondroitin sulfate.

It seems that although metachromatic solutions containing chondroitin sulfate have spectra varying continuously with the proportions of dye, chromotrope, and salt content, there is, at least dominantly, a single compound responsible for the metachromatic colour in solution. The essential requirements for production of a metachromatic colour are a cationic dye which in water solution shows large deviations from Beer's law, and an anionic polyelectrolyte. It would thus be natural to imagine that the metachromasia in pineal gland can be due to high levels of chondroitin sulphate. Studies have shown that local factor responsible for calcification in tissues is chondroitin sulphate. Being sulphated, it might exhibit metachromasia [20]. Methylene blue (Classification Index 52015) is a heterocyclic aromatic compound, with the molecular formula $\mathrm{C}_{16} \mathrm{H}_{18} \mathrm{~N}_{3} \mathrm{SCl}$. It is odourless powder yielding blue colour when dissolved in water. Methylene blue is used in the presumptive identification of Corynebacterium diphtheria. M etachromasia, a condition characteristically seen in Corynebacterium diphtheria, is due to an accumulation of polymerized polyphosphates in high concentration inside the cell. This condition appears as polyphosphate granules stained deeply blue, surrounded by lighter blue stained cytoplasm, and are often called BabesErnst bodies or metachromatic granules. Methylene blue, is also recommended for use in the staining of gram-negative bacteria found in spinal fluid, namely Haemophilus influenzae and Neisseria meningitidis. In addition to the staining of microorganisms, M ethylene Blue was demonstrated by Harris in 1972 to be an effective stain for the enumeration of leukocytes in mucus or feces [21]. The present study elicits the uses of methylene blue to demonstrate metachromasia.

Clinical significance: Pineal gland is of clinical 
significance because deficiency of melatonin exacerbates depression, peptic ulcers, and sexual dysfunction. Studies have found that stress and dietary habits may lead to deficiencies of both serotonin and melatonin. One of the key functions of melatonin is to inhibit the release of cortisol via the release of vasotocin. Abnormal circadian rhythms of cortisol may occur in states of decreased melatonin. A circannual rhythm of melatonin has troughs associated with peaks in the incidence of peptic ulcers and psychotic depression. Psychotic depression is an apparent disorder of the locus ceruleus and/or dorsal raphe nucleus [18]. The pineal gland has been implicated in a number of disorders including cancer, sexual dysfunction, hypertension, epilepsy, Paget's disease. The pineal gland calcifies with age and melatonin production correspondingly decreases. This decline in melatonin has been suggested to be a trigger for the aging process [22].

The presence of melanin in pineal gland can be attributed to melatonin suppression by melanocyte stimulating hormone which prevents dispersion of melanin granules. The melanin pigments became concentrated in the pineal gland. However, it can be demonstrated by special staining methods such as Masson's Fontana technique [18].

Limitations: The metachromatic shift of methylene blue in tissues is usually from blue to red or yellow. In the present study, however distemper green colour is demonstrated by corpora arynecea. This can be attributed to the fact that ability to change to red colour by corpora arynecea can be obtained at the wavelength of $480-540 \mathrm{~nm}$. The study can be directed in achieving this by standardising hydration, $\mathrm{PH}$ and temperature. Secondly, histochemical analysis of corpora arynecea is to be done to measure levels of chondroitin sulfate contributing to metachromasia.

\section{CONCLUSION}

Pineal gland is evolutionarily close to retina. Intrapineal calcification is globular or concentric lamellar type. Calcification shows metachromasia with aqueous methylene blue. In comparison to hematoxylin and eosin staining, modified Lendrum's technique stains brain sand of pineal gland brilliantly. The gland is clinically important standard indicator of midline position in CT/ M RI's and radiographs.

\section{ABBREVIATIONS \\ DPX - Distyrene Plasticizer Xylene}

\section{ACKNOWLEDGEM ENTS}

I thank my colleagues Dr. Balachandra N, Dr. Poonam DN, Dr. Shylaja DK for their substantial contributions to conception, design, acquisition of data, analysis and interpretation of data, and revising the manuscript.

\section{Conflicts of Interests: None}

\section{REFERENCES}

[1]. Culling CFA, Allison RT, Barr WT. Handbook of histopathological techniques. $4^{\text {th }}$ edition Edited by Butterworths. London; 1963: 242, 151466.

[2]. Epstein M A . International review of connective tissue research. Calcification of skeletal tissues. Volume 1. 351. [https://books.google.co.in/ books?id=27_YBAAAQBAI\&dq=metachromasiatof+calcium \&source=gbs_navlinks_s]

[3]. Lucy KM, Härshan KR, Chungath JJ, Ashok N. Histomorphogenesis of Pineal gland in goat foetuses. J. Vet. Anim.Sci 2011;42:16-19.

[4]. Anna Taraszewska, Ewa M atyja, Waldemar Koszewski. Asymptomatic and symptomatic glial cysts of the pineal gland. Folia Neuropathol 2008;46(3):186195.

[5]. Pal B, Ghosal AK, M inj AP, Ghosh RK. Comparative histomorphological study of the pineal gland in human and fowl. Al Ameen J M ed Sc i 2013;6(1):8084.

[6]. Sidney B Lang, Andrew A M arino, Garry Berkovic C. Piezoelectricity in the human pineal gland. Bioclectrochemistry and Bioenergetics 1996;41: 191-195.

[7]. Safwat Ebada. Morphological and Immunohistochemical Studies on the Pineal Gland of the Donkey (Equus asinus). J. Vet. Anat. 2012;5(1):47-74.

[8]. Bala Vigh, Riihlich PA, Tam \& Gijrcs, Maria Jotio Manzano. The pineal organ as a folded retina: Immunocytochemical localization of opsins. Biology of the Cell 1998;90:653-659.

[9]. Masayuki Sumida, James Barkovich A, and Hans Newton T. Development of the Pineal Gland: M easurement with MR. AJNR Am J Neuroradiol 1996; 17:233-236.

[10]. Srinivasan V. The pineal gland: Its physiological and pharmacological role. Ind. J. Physiol. Pharmac 1989;33(4):263-272.

[11]. Bancroft JD, Stevens A. Theory and practice of histological technique.3rd edition. Churchill Livingstone, London, UK, 1990. 
[12]. Koshy S, Vettivel SK. Varying Appearances of Calcification in Human Pineal Gland: A Light Microscopic Study. J Anat. Soc. India 2001;50(1):17-18.

[13]. Richard W Horobin, How Do Dyes Impart Color to Different Components of the Tissues? Chapter 18. Special stains and H \& E .159-166.

[14]. Levidou . Low-grade oligodendroglioma of the pineal gland: A case report and review of the literature. Diagnostic Pathology 2010;5:59.

[15]. Michael Titford. Progress in the Development of Microscopical Techniques for Diagnostic Pathology. The Journal of Histotechnology 2009;32(1):919.

[16]. Metachromatic staining. Histology and cytology. Chapter 12. 78-82.Accessed on 19/10/2016http:// www.nos.org/media/documents/dmlt/HC/Lesson12.pdf

[17]. M edini Kanta Palt , M axwell Schubert. Specific adsorption of metachromatic compounds of chondroitin sulfate by insoluble calcium salts. Downloaded from jhc.sagepub.com on April 9, 2015

[18]. Gokul Sridharan , Akhil A Shankar. Toluidine blue: A review of its chemistry and clinical utility. J Oral Maxillofac Pathol 2012;16(2):251-255.
[19]. Maurizi CP. Disorder of the pineal gland associated with depression, peptic ulcers, and sexual dysfunction. South Med J 1984;77(12):1516-8.

[20]. Adonai. Why pineal gland and mental health are most important in these times. Posted on January 24, 2012 in categories Cosmic evolution, Editors' picks, Health,Social evolution. http://thewatchers .adorraeli.com/2012/01/24/ why-pineal-gland-andmental-health-are-most-important-in-these-times/ accessed on 19/4/2015

[21].Methylene blue, Loefflers https://catalog. hardydiagnostics.com/cp_prod/Content/hugo/ MethyleneBlueLoefflers.htm accessed on 19/4/2015.

[22].Kriengkrai Urusopon, Umphaphorn Pornkunnatham, Jantima Roongruangchai, Kesorn Sripaoraya, Yadaridee Viravud. The Histology of the Pineal Gland in Cadaveric Embalmed Specimens. Siriraj Med J 2012;64(1):S54-S57.

\footnotetext{
How to cite this article:

Vasudha Kulkarni, Ramesh BR. MODIFIED LENDRUM'S TECHNIQUE TO DEM ONSTRATE METACHROM ASIA OF BRAIN SANDIN PINEAL GLAND. Int J Anat Res 2017;5(1):3415-3420. DOI: 10.16965/ijar.2016.492
} 